\begin{tabular}{|c|c|c|c|}
\hline \multirow{2}{*}{$\begin{array}{r}\text { Case Reports in } \\
\text { Gastroenterology }\end{array}$} & \multicolumn{2}{|c|}{ Case Rep Gastroenterol 2016;10:819-825 } & \multirow[b]{2}{*}{$\begin{array}{l}\text { Karger } \\
\text { Open access }\end{array}$} \\
\hline & $\begin{array}{l}\text { DOI: } 10.1159 / 000453656 \\
\text { Publisned onme: January 6, } 2017\end{array}$ & $\begin{array}{l}\text { (c) } 2017 \text { The Author(s) } \\
\text { Published by S. Karger AG, Basel } \\
\text { www.karger.com/crg }\end{array}$ & \\
\hline & $\begin{array}{l}\text { This article is licensed under th } \\
\text { International License (CC BY-NC } \\
\text { Usage and distribution for comme }\end{array}$ & $\begin{array}{l}\text { nons Attribution-NonCommerc } \\
\text { ger.com/Services/OpenAccessLi } \\
\text { uires written permission. }\end{array}$ & \\
\hline
\end{tabular}

\title{
Agenesis of the Gallbladder: Role of Clinical Suspicion and Magnetic Resonance to Avoid Unnecessary Surgery
}

\author{
Eugenio Tagliaferri $^{\mathrm{a}} \quad$ Heinrich Bergmann $^{\mathrm{a}}$ Sebastian Hammans ${ }^{\mathrm{a}}$ \\ Aziz Shiraz $^{\mathrm{b}} \quad$ Eckhard Stüber $^{\mathrm{c}}$ Christoph Seidlmayer ${ }^{\mathrm{a}}$ \\ ${ }^{a}$ Department of Surgery, Bonifatius Hospital, Lingen, Germany; ${ }^{b}$ Department of Radiology, \\ Bonifatius Hospital, Lingen, Germany; ' Department of Gastroenterology, Bonifatius \\ Hospital, Lingen, Germany
}

\section{Keywords}

Gallbladder agenesis · Biliary colic · Conservative management - Magnetic resonance cholangiopancreatography

\begin{abstract}
Isolated agenesis of the gallbladder is usually a rare asymptomatic anatomical variation, with an estimated incidence of 10-65 per 100,000. Females are more commonly affected (ratio 3:1), with the disease typically presenting in the second or third decade of their life. Despite an absent gallbladder, half of the patients present with symptoms similar to biliary colic, which is poorly understood. The rarity of this condition combined with its clinical and radiological features often lead to a wrong preoperative diagnosis so that many patients undergo unnecessary operative intervention. Herein, we present the case of a 56-year-old female with a typical biliary colic who was diagnosed to have gallbladder agenesis. Computed tomography and magnetic resonance cholangiopancreatography allowed correct treatment and prevented an unnecessary intervention.

(C) 2017 The Author(s) Published by S. Karger AG, Basel
\end{abstract}




\section{Introduction}

Isolated agenesis of the Gallbladder is usually a rare asymptomatic anatomical variation, with an estimated incidence of 10-65 per 100,000. Females are more commonly affected (ratio 3:1), with the disease typically presenting in the second or third decade of their life. The first reports of cases of gallbladder agenesis date back to 1701 and 1702 and were written by Lemery and Bergman [1-3].

The pathogenesis is related to the embryonic development and is due to failure of the gallbladder and cystic duct to bud off from the common bile duct during the fifth week of gestation [4,5]. Despite an absent gallbladder, half of the patients present symptoms similar to biliary colic, which is poorly understood. The rarity of this condition combined with clinical and radiological features often lead to a wrong preoperative diagnosis so that many patients undergo unnecessary operative intervention.

We present the case of a 56-year-old female who showed a typical biliary colic and was diagnosed to have gallbladder agenesis upon computed tomography (CT) and magnetic resonance cholangiopancreatography (MRCP). The lack of visualization of the gallbladder on ultrasound combined the clinical suspicion of a congenital abnormality of the biliary tree led to the confirmation of the diagnosis by MR imaging, which avoided an unnecessary surgery and allowed the appropriate conservative treatment for the patient.

\section{Case Presentation}

A 56-year-old female presented to the hospital with right upper-quadrant pain. In the medical history that she reported, she was in her usual state of health. She had no prior surgical background. She was taking oral contraceptive pills and had no known drug allergies. The pain was located in her right upper quadrant, dull, aching in quality, sudden in onset, colic in nature, and radiated to her right scapula. Her blood pressure and pulse rate were regular, and her body temperature was $36.8^{\circ} \mathrm{C}$. No other symptoms were associated. The pain disappeared with the intravenous administration of antispasmodics.

With respect to her family background, her mother had a cholecystectomy before at the age of 50 due to gallstone disease. The patient was admitted to the emergency department and was evaluated by the surgical service. The abdominal ultrasound showed prominence of the common bile duct $(11 \mathrm{~mm})$ without intrahepatic biliary dilatation and no visualization of the gallbladder (Fig. 1). The laboratory testing was notable for an unremarkable basic metabolic panel (C-reactive protein: $7 \mathrm{mg} / \mathrm{L}$; alkaline phosphatase: $35 \mathrm{U} / \mathrm{L}$ ) and liver enzymes (glutamic oxalacetic transaminase $25 \mathrm{U} / \mathrm{L}$; glutamate-pyruvat-transaminase $30 \mathrm{U} / \mathrm{L}$; glutamyltransferase: $37 \mathrm{U} / \mathrm{L}$, and total bilirubin $19 \mu \mathrm{mol} / \mathrm{L}$ ). The patient was admitted to the hospital upon suspicion of a retracted gallbladder by a chronic cholecystitis and underwent an endoscopic ultrasound at the gastroenterologist service that showed a prominent bile duct without gallstones. A CT scan was obtained and was read by the radiologist as "status postcholecystectomy" by nonvisualization of the gallbladder on ultrasound as well as a CT scan (Fig. 2a, b). An MRCP was ordered, which revealed the absence of both the gallbladder and cystic duct, consistent with gallbladder agenesis (Fig. 3). At this point, a gastroenterology consult was made for assistance for further conservative management with smoothmuscle relaxants. 


\section{Discussion}

Agenesis of the gallbladder is a rare congenital anomaly [6]. The incidence in the general population is reported as $13-65$ cases per 100,000 . In clinical series, the incidence is $0.007-$ $0.0027 \%[7,8]$, while in autopsy series, it is $0.04-0.13 \%$ [9]. About $50 \%$ of the patients present symptoms of biliary disease [1]. There is also a strong predominance of females among the symptomatic cases.

The liver, gallbladder, and biliary system begin to develop early in the fourth week of intrauterine life as a ventral outgrowth from the caudal part of the foregut. This hepatic diverticulum divides into 2 parts as it grows, one representing the primordium of the liver and the other the primordium of the gallbladder and cystic duct. By the seventh week, vacuolation occurs, and the gallbladder and cystic duct develop a lumen. Failure of this developmental process at any stage results in agenesis of the gallbladder, whereas inappropriate migration of the gallbladder primordium will result in an ectopic gallbladder. Potential sites of ectopic gallbladder are intrahepatic, left-sided, beneath the posterior inferior surface of the liver, between the leaves of the lesser omentum within the falciform ligament, retroperitoneal, retrohepatic, or in the retropancreatic and retroduodenal areas [5].

Clinically, 3 groups of gallbladder agenesis have been described: (1) asymptomatic (an incidental finding at laparotomy for another reason; 35\%), (2) symptomatic (50\%), and (3) in children with multiple fetal anomalies (such as tetralogy of Fallot and agenesis of the lungs) who die in the perinatal period (15-16\%) [1,10].

The symptoms in patients with gallbladder agenesis are explained by the theory of biliary dyskinesia, to be specific: sphincter of Oddi dysfunction. In animals, it has been found that gallbladder agenesis involves anomalies of the sphincter of Oddi. Similarly, it is well acknowledged that when a spasm of the sphincter of Oddi is induced, the symptoms of biliary colic are reproduced [11].

Historically, all cases were identified intraoperatively despite the high resolution of diagnostic imaging techniques. It has been proven to be very difficult to make a correct preoperative diagnosis of agenesis of the gallbladder in symptomatic patients, and until now, many cases are still diagnosed intraoperatively $[3,12,13]$.

When laparoscopic surgery is done, the risk of iatrogenic injury is higher and the associated morbidity of the procedure is greater, especially for a surgeon with little experience in hepatobiliary surgery. Thus, preoperative diagnosis is mandatory but it depends on a "suspected gallbladder agenesis".

In the vast majority of cases, imaging studies may report a contracted gallbladder or one with gallstones, which perhaps is due to a misinterpretation of the images that probably correspond to dilated bile duct or choledocholithiasis. In some cases, when the gallbladder is not seen, this is attributed to various reasons, such as bloating or intestinal loops which overlap, but the vesicular agenesis is the least-common possible explanation. Ectopic gallbladder should be noted as it can be demonstrated by other diagnostic studies. Sometimes the diagnosis is achieved without surgery; some cases have been detected by clinical suspicion and confirmation by MRCP. It is not unusual for patients undergoing surgery to have several previous ultrasounds, but some of these might not have been able to visualize the biliary gallbladder or might have revealed a "scleroatrophic" gallbladder.

Symptomatic patients with agenesis of the gallbladder commonly present right upperquadrant pain, dyspepsia, jaundice, fatty food intolerance, or nausea, but these symptoms are indistinguishable from those of other common biliary tract conditions [14]. Therefore, 
the presumptive diagnosis is primarily that of a biliary tract pathology, the most common of which is biliary colic caused by a gallstone.

The usual initial investigation for patients presenting with right upper-quadrant pain is an abdominal ultrasound. The ultrasound has a reported sensitivity of 95\% in diagnosing gallstones but is dependent on many factors, including the operator's experience and the examination conditions. Gallbladder agenesis cannot be reliably differentiated from the shrunken, contracted gallbladder of chronic cholecystitis, and this is the most frequent radiologic report seen in patients later found to have agenesis of the gallbladder. It has been suggested that the absence of the ultrasonographic features of the WES triad (visualization of the gallbladder wall, the echo of the stone, and the acoustic shadow) and the double-arc shadow should raise suspicion of gallbladder agenesis as the diagnosis $[4,15]$.

MRCP is a noninvasive and well-demonstrated imaging method in the evaluation of the biliary tract $[5,16,17]$. As it does not require contrast administration to visualize the bile, it is not compromised by biliary stasis.

It can also demonstrate an excluded and/or ectopic gallbladder. In our case, MRCP allowed to make the correct preoperative diagnosis by a noninvasive examination, avoiding unnecessary surgical exploration and minimizing the risk of complications. Moreover, it provided accurate anatomical details about the bile tree, leading to the exclusion of the condition of ectopic gallbladder.

The MRCP technique may not yet replace ultrasound as the gold standard of acute gallbladder imaging but it has shown to be an ideal complementary study to inconclusive ultrasonographic studies. In our case, early suspicion of malformations in the bile duct by the surgical team and confirmation of the diagnosis through MR imaging prevented unnecessary surgery and ruled out any other type of malformation of the bile ducts or stones in the common bile duct. Our patient responded well to the conservative treatment with antispasmodics, which is still controlled in ambulatory care.

\section{Conclusion}

Agenesis of the gallbladder is a very rare condition with no specific symptoms that can often pose a dilemma to surgeons because it is usually diagnosed during a laparoscopic cholecystectomy. The patients without a gallbladder are usually operated because of a "false" interpretation of ultrasound imaging. When ultrasound examination reveals a "scleroatrophic" gallbladder or when the gallbladder cannot be visualized by other imaging modalities, we have to suspect congenital agenesis.

With the advances in imaging techniques, some cases of gallbladder agenesis are diagnosed incidentally and outside of the operating room. Clinicians should have a strong index of suspicion if nonvisualization is suggested by an ultrasound examination, and furthermore, preoperative investigation is necessary, primarily a MRCP. This method of diagnosis is considered the test of choice if there is suspicion. MRCP is also helpful in demonstrating an ectopic gallbladder along with other possible anomalies of the biliary tract system.

The combination of an early suspicion of an abnormal biliary tract and the realization of a preoperative MRCP is the diagnostic test of choice to avoid unnecessary surgeries. 


\section{Acknowledgements}

We are deeply indebted to the patient for allowing us to present her information as a case report. Special thanks to Natalia and Gustavo Tagliaferri, Patricia Cadavid, and Jackie Lou Abad who helped with the correction of the paper.

\section{Statement of Ethics}

This article has been done according to the World Medical Association Declaration of Helsinki Ethical Principles for Medical Research Involving Human Subjects.

\section{Disclosure Statement}

The authors declare that they have no competing interests.

\section{References}

1 Bennion RS, Thompson JE, Tompkin RK: Agenesis of the gallbladder without extrahepatic biliary atresia. Arch Surg 1988;123:1257-1260.

-2 Mittal A, Singal S, Singal R, Mehta V: Gallbladder agenesis with common bile duct stone: a rare case with a brief review of the literature. Turk J Gastroenterol 2011;22:216-218.

3 Malde S: Gallbladder agenesis diagnosed intra-operatively: a case report. J Med Case Rep 2010;4:285.

4 Gotohda N, Itano S, Horiki S, et al: Gallbladder agenesis with no other biliary tract abnormality: report of a case and review of the literature. J Hepatobiliary Pancreat Surg 2000;7:327-330.

5 Fiaschetti V, Calabrese G, Viarani S, Bazzocchi G, Simonetti G: Gallbladder agenesis and cystic duct absence in an adult patient diagnosed by magnetic resonance cholangiography: report of a case and review of the literature. Case Rep Med 2009;2009:674768.

-6 Kasi PM, Ramirez R, Rogal SS, Littleton K, Fasanella KE: Gallbladder agenesis. Case Rep Gastroenterol 2011;5:654-662.

-7 Ahlberg J, Angelin B, Einarsson K, Leijd B: Biliary lipid composition and bile acid kinetics in patients with agenesis of the gallbladder with a note on the frequency of this anomaly. Acta Chir Scand 1978;482:15-20.

-8 Ferris DO, Glazer IM: Congenital absence of gallbladder. Four surgical cases. Arch Surg 1965;91:359361.

Monroe SE, Ragen FJ: Congenital absence of the gallbladder. Calif Med 1956;85:422-423.

10 Venuta A, Laudizi L, Miceli F, Pantusa M, Laudizi Z: Agenesis of the gallbladder. Description of 2 cases in 2 siblings (in Italian). Pediatr Med Chir 1989;11:465-466.

-11 Toouli J, Geenen JE, Hogan WJ, Dodds WJ, Arndorfer RC: Sphincter of Oddi motor activity: a comparison between patients with common bile duct stones and controls. Gastroenterology 1982;82:111-117.

12 Grandhi TM, El-Rabaa SM: Agenesis of the gallbladder and cystic duct: laparoscopic diagnosis. The Internet J of Gastroenterology 2005;4:1.

13 O'Sullivan J, O'Brien PA, MacFeely L, Whelton MJ: Congenital absence of the gallbladder and cystic duct: nonoperative diagnosis. Am J Gastroenterol 1987;82:1190-1192.

14 Haughton V, Lewicki AW: Agenesis of the gallbladder. Is preoperative diagnosis possible? Radiology 1973;106:305-306.

15 Rybicki FJ: The WES sign. Radiology 2000;214:881-882.

16 Fulcher AS, Turner MA, Capps GW: MR cholangiography: technical advances and clinical applications. Radiographics 1999;19:25-41; discussion 41-44.

17 Pierro A, Martucci M, Maselli G, Farchione A: Agenesis of the gallbladder with the presence of a small dysmorphic cyst: role of magnetic resonance cholangiopancreatography. J Clin Imaging Sci 2012;2:17. 


\section{Case Reports in Gastroenterology}

\begin{tabular}{l|l}
\hline Case Rep Gastroenterol 2016;10:819-825 \\
\hline DOI: 10.1159/000453656 & $\begin{array}{l}\text { @ 2017 The Author(s). Published by S. Karger AG, Basel } \\
\text { www.karger.com/crg }\end{array}$ \\
\hline
\end{tabular}

Tagliaferri et al.: Agenesis of the Gallbladder: Role of Clinical Suspicion and Magnetic Resonance to Avoid Unnecessary Surgery

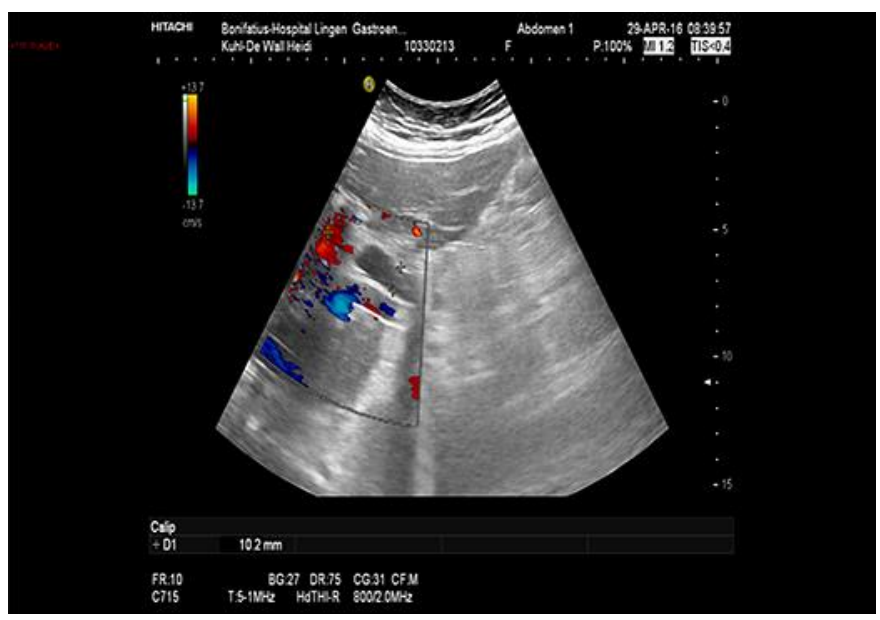

Fig. 1. Sonography of the biliary system demonstrating an 11-mm dilatation of the common hepatic duct and no evidence of the gallbladder.
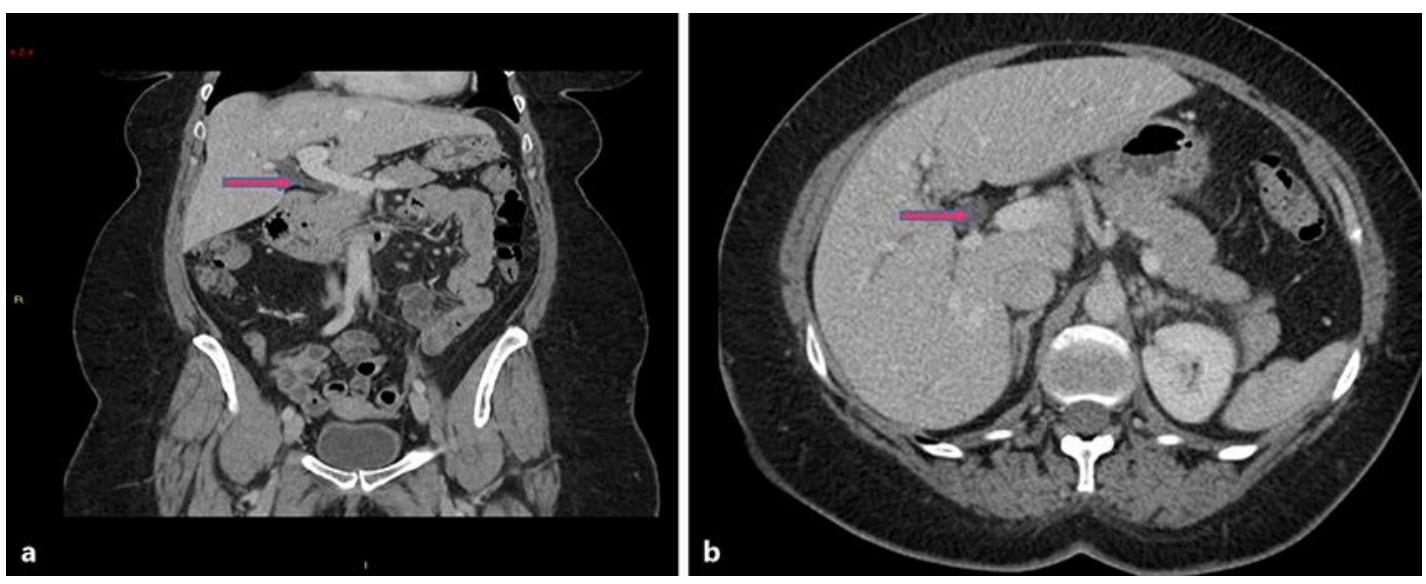

Fig. 2. a Coronary computed tomography scan of the liver and biliary system demonstrating dilatation of the common hepatic duct and absence of the gallbladder and cystic duct (red arrow). b Axial computed tomography scan of the hepatobiliary system revealing absence of the gallbladder and cystic duct and dilatation of the common hepatic duct (red arrow). The image was read by the radiologist as "status postcholecystectomy". 


\section{Case Reports in Gastroenterology}

Case Rep Gastroenterol 2016;10:819-825 DOI: $10.1159 / 000453656$ (c) 2017 The www.karger.com/crg

Tagliaferri et al.: Agenesis of the Gallbladder: Role of Clinical Suspicion and Magnetic Resonance to Avoid Unnecessary Surgery

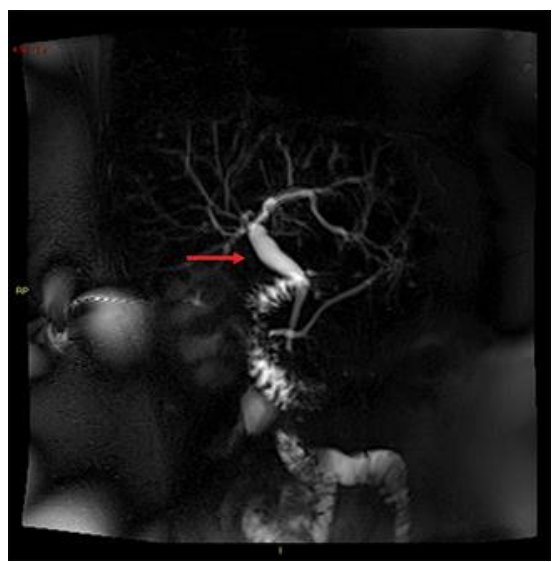

Fig. 3. Magnetic resonance cholangiopancreatography (MRCP) represents agenesis of the gallbladder, confirming agenesis of the gallbladder and cystic duct (red arrow). MRCP is considered the test of choice if there is suspicion of a hypoplastic gallbladder. It is also helpful in demonstrating an ectopic gallbladder along with other possible anomalies of the biliary tract system. 